\title{
Pauses and Hesitations in Drama Texts
}

\author{
Nawal Fadhil Abbas ${ }^{1}$, Ru'aa Tariq Jawad ${ }^{1} \&$ Maysoon Tahir Muhi ${ }^{1}$ \\ ${ }^{1}$ College of Education for Women, University of Baghdad, Baghdad, Iraq \\ Correspondence: Nawal Fadhil Abbas, College of Education for Women, University of Baghdad, Baghdad, Iraq. \\ E-mail: nawal-fa71@yahoo.com
}

$\begin{aligned} & \text { Received: February 20,2018 } \\ & \text { Accepted: March 5, } 2018 \quad \text { Online Published: March 17, } 2018 \\ & \text { doi:10.5539/ijel.v8n4p106 }\end{aligned}$ URL: https://doi.org/10.5539/ijel.v8n4p106

\begin{abstract}
Pauses and hesitations are phenomena that can be found in speech. They can help both the speaker and the hearer, due to the functions they have in a dialogue. Their occurrence in speech has a value that they make it more understandable. In this regard, the researchers intend to critically examine the pauses and hesitations used in the two texts as well as their functions. The present paper aims to identify the types of pauses and hesitations used by Pinter's The Homecoming and Baker's Circle Mirror Transformation as well as the functions they serve and to compare both playwrights in this regard. To do so, the sequential production approach of turn taking, in combination with the contributions of some scholars who state the multifunctional use of pauses and hesitations, has been used. The findings of the present study show that pauses and hesitations do not exist arbitrarily in speech but they are found to serve certain functions depending on the context in which they occur. Regarding the two selected extracts, it is noticed from the comparison that the two writers do not use pauses and hesitations equally. Baker uses them more frequently than Pinter due to the context in which they are used which requires using pauses to aid comprehension.
\end{abstract}

Keywords: pauses, hesitations, filled pauses, silent pauses

\section{Introduction}

Pragmatic markers are signals or cues that help the hearer (or reader) understand utterances and interpret them in the right way. In addition, these markers make speech or writing more cohesive by relating what is said to what is said earlier. Pauses and hesitations are considered as a type of pragmatic markers. The study of the phenomena of pauses and hesitation can be traced back to at least the 1950s (Maclay \& Osgood, 1959). Since then many studies have been conducted for the investigation of pauses and their functions in discourse (Stenstorm, 2011). These studies have shown that pauses are of two types: silent pauses and filled pauses. Scholars also show that hesitation phenomenon is expressed by the use of pauses and other hesitation markers. Some linguists consider pauses as meaningless. They only serve to organize discourse (Bruneau, 1973). Other studies show the wrongness of this idea because these pragmatic markers have indications and functions. They guide the hearer or the reader to potentially interpret a conversation according to the context (Fox Tree \& Schrock, 1999; Fox Tree, 2007). Moreover, pauses and hesitations phenomena have been studied in different languages such as English and Japanese. Many recent studies have been even carried to investigate the use of pauses and hesitation by non nativespeakers (Watanabe \& Rose, 2012). On the whole, it is worth mentioning that the uses of pauses and hesitation have been studied by native and non-native speakers of English as well (Watanabe \& Rose, 2012).

Although pauses and hesitations are very obvious in spoken discourse, they can be studied in written discourse. For example, many playwrights use certain words and interjections like $a h$ and other markers of pauses like triples, ellipsis and dashes to show that there is a pause or hesitation. Other times they use phrases such as "short pause" and "long pause" (O Connel \& Kowal, 2004). The hesitation phenomenon is connected with pauses since one of the functions of pauses is "indicating hesitancy" (Crystal, 2008). Moreover, hesitations indicate that the person is not really sure about what to say. In this regard, the researchers of the present study intends to examine two extracts from two plays by Pinter and Baker. To do so, they will adopt the sequential production approach of Sacks et al. (1974) in combination with the contributions of some other scholars that show the multifunctional use of pauses in order to achieve the objectives of the study which read as: (1) Examimning the types of pauses and hesitations, (2) Examining the role that pauses play, (3) Coparing how the two writers use pauses and hesitationst. 


\section{Literature Review}

The following sections provide an account regarding pauses and hesitations, their types as well as the functions that pauses may perform.

\subsection{What is A Pause?}

Pauses are considered as a very necessary part of speech. Different studies have mentioned that the percentage of pause duration ranges from $20 \%$ to $50 \%$ of the total duration of speech in "real speech" and from $30 \%$ to $46 \%$ in "spontaneous speech". Hesitations can be expressed by means of pauses. Pauses are either silent or filled. Fillers are used to fill pauses and express hesitancy. Fillers are either meaningless which are "non-lexical items". Uh and $u m$ are examples of meaningless fillers in English language. On the other hand, there are fillers, for example; well, like, you know, which are examples of "lexical items" (Yuan, Xu, Lai, \& Liberman, 2000). From a linguistic point of view, there is an opinion which considers pauses as markers of "speech disfluencies". Lately, pauses are presented as being a valuable aspect in speech and linguists have become interested in the various functions of them (Teiller, Stam, \& Bigi, 2013). Wang \& Li (2014, p. 125) state that a "pause means a break in speaking or a moment of silence". According to Richards and Schmidt a pause is "a commonly occurring feature of natural speech in which gaps or hesitations appear during the production of utterances" (2010, p. 424). Pauses are "referred to as silence, hesitation and junctures" (Cecot, 2006, p. 65). Pauses are considered as a type of discourse markers.

The widespread idea about markers such as um, uh, you know, like and well is that they have no meaning. They just serve to organize discourse, however; studies have shown the wrongness of this idea because these markers have indications and functions (Fox Tree, 2007). For example $u m$ is used to indicate an upcoming delay or it can suggest that the person talking is lying, also it helps in conversation management (Fox Tree, 2010). Thus, they have communicative functions in the context in which they are used. They have many different functions. These functions can be traced according to the context in which they occur. Pauses are not only used according to the way users intend them to mean. Some studies have been done to show how these pauses are interpreted by people themselves and how they use them. For example; a study conducted by Fox Tree (2007) has shown that for "um, uh and you know, there is some evidence that people from the same speech community are in fact using the markers in the way that they intuitively verbalize that the markers are used" (Fox Tree, 2007, p. 310).

According to Goldman-Eisler pauses do not exist in speech randomly. They are used to serve certain functions. Besides, she has recognized the difference between breathing pauses and hesitation pauses. In one of her studies Goldman-Eisler has come up with the following conclusion "the first lexical item after a silent pause is more difficult to predict than any lexical item uttered in a fluent context." According to this study silent pauses are used in order to have enough time to process what they want to say (as cited in Tissi, 2000, p. 106).

\subsubsection{Types of Pauses}

Pauses are of two types: silent pauses and filled pauses

\subsubsection{Silent Pauses}

Silent or unfilled pauses are breaks in the speech production and they differ in length, i.e., short or long (Crystal, 2008). Punctuation is considered as a way of expressing pauses in writing. In speech Pauses have relation "with tone unit" boundaries. These pauses are important for both the speakers and the listeners, that it helps the speaker organize what he/she wants to say, and give time to the hearer to think about what is said. They perform the action of making the boundaries of words in addition to being interactional devices and they mark emphasis (Stenstrom, 2011). A silent pause is "any interval of the escillograph trace where the amplitude is indistinguishable from that of the background noise" (Cecot, 2001, p. 69).

\subsubsection{Filled Pauses}

Filled pauses are defined by Crystal as "a term used by linguists to refer to non-silent pause that is to say hesitation which has been "filled" by er, erm or some vocalization" (Crystal, 2008, p. 188). The way filled pauses are expressed differently is decided by the language. In each language pauses are expressed differently (Stenstrom, 2011), for example; $u h$ and $u m$ are used in American English, er and erm are used in British English, in Spanish the usage of $u h$ and um are noticed etc. (Weiling et al., 2016).

Filled pauses are different as long as length is concerned. Colon is a way of referring to long filled pauses, for example; (e:r, e:rm) (Stenstrom, 2011). According to Straweather (1980) fluency in speaking does not necessarily mean speech which is devoided of pauses. Rather, it means to speak with a reasonable number of pauses and hesitations that constitutes one of the features of natural conversation (as cited in Cecot, 2001). 


\subsection{What is Hesitation?}

The occurrence of hesitations in any language is a feature of natural speech. Hesitations phenomena appear during speaking when the participant does not know what to say in order to express a particular idea in his/her mind. Hesitation pauses are of various types. They are either silent pauses or filled pauses. Pauses are considered as a way of expressing hesitancy (Stepanova, 2007). The reason behind the relationship between pauses and hesitations is that expressing hesitancy is one of the functions of pauses (Ekland \& Wiren, 2010). Hesitation "is a term used by linguists especially in psycholinguistics in which this phenomenon is studied in relation language processing" (Crystal, 2008, p. 227). Hesitation pauses are often filled either with verbal fillers or non-verbal actions (for example; gestures). Verbal fillers include expressions such as uh, err, ahem, erm, hmm, muh, you know, let's, well etc. Non-verbal actions include using hand movement, gazing etc. (Rieger, 2001). Hesitations convey that the speaker is not sure about what to say. Besides, hesitations are used for managing conversation properly while the speaker formulates what he/she wants to say (Clark \& Fox Tree, 2002).

\subsubsection{Types of Hesitations}

It is mentioned earlier that both silent and filled pauses are one of the ways that speaker can use to convey hesitancy. Furthermore, there are other ways of expressing hesitancy which are mentioned by Stenstrom (2011) and as follows:

\subsubsection{Verbal Fillers}

Hesitations are expressed by means of verbal fillers by using expressions like you know, like, well, sort of and so on. These expressions imply more than one function. In spite of being gap fillers in the conversation, they also have different pragmatic, interactional and discourse functions. Concerning verbal fillers, in addition to being a way of expressing hesitancy, they play a role and have a value in turn-taking system as they can serve as a turn-holder. They can also be used to yield the turn. Besides, they give the participant time which he/she needs in order to think about what he/she wants to say.

\subsubsection{Lengthenings}

Lengthenings include making a word longer by repeating a certain letter whether it is a conjunction, for example; (aaand) or articles like (thee). They are used as a strategy to have enough time to plan their ideas.

\subsubsection{Repetitions}

Repetitions include repeating a word more than one time. This happens with prepositions, like (to to to), articles, like, (the the the), pronouns (I I I) as well as conjunction, like (and and). They provide the participant with enough time needed for processing and thinking of what to say next. They tend to occur in initial-position when the speaker continues talking about a certain topic after digression. Besides, Watanabe \& Rose (2012) call the repetition that occurs in initial position as a "restart".

\subsubsection{Repairs}

Repairs have an influence on lexical words in general. The speaker selects among different words for the sake of improving his/her pronunciation. Repairs are usually preceded by a "verbal filler or a filled pause" (Fox Tree \& Schrock, 2002). Watanabe \& Rose (2012) state that repairs are a succession of words function to repair or correct to the hearer what he/she understands in a preceding utterance. In case repairs occur in initial position, they are called a "false start".

\subsubsection{Reformulations and Restarts}

There is a tendency for reformulations to occur in initial-position or when the speakers shifts from one topic to another. Conjunctions, for example; and, but, so can play a role of bridge between two utterances, similar to verbal fillers and filled pauses. The speaker can have a new start to reformulate what he/she has produced.

\subsection{Functions of Pauses and Hesitations}

During the process of speech production speakers manipulate fillers which are considered as discourse markers. Speakers tend to use fillers to fill the gaps when they are thinking about what to say. According to Clark \& Fox Tree (2002) that fillers play a communicative function in speaking. Researchers state that fillers do not convey a main message but a secondary one, that is to say they are tools to facilitate understanding the meaning during communication but not the meaning itself. Pauses have important roles during oral communication. They play an interactional role that they help a speaker in holding a turn in a conversation in addition to expressing thinking and mental states. Some researchers see filled pauses as being unwanted, needless and annoying to listener so that people try to learn how to avoid using them by taking special courses. Tsiaras, Panagiotakis, \& Stylianou 
(2009) state that pauses have many functions. The researchers of the present study side with those who emphasize the importance of studying the functions of these pauses as fillers like Maclay \& Osgood (1959); Zellner (1994) and Clark \& Fox Tree (2002).

In this regard, the existence of a pause is decided by a number of factors, for example; showing emphasis, anxiety, interrupting the speaker, intersubjectivity, having a breath, availability, syntactic complexity and so on (Oliveria, 2002). Pauses normally exist at important points in discourse. Besides, they have an influence upon the rhyme as well as intonation. It is noticed that pauses are an important part of interaction and have a communicative value. Moreover, silent and filled pauses represent a mechanical reaction to the problems of speech planning which increase as a result to cognitive loads needed for deception (which is one of the functions of pauses and hesitations markers) (Benus, Enos, Hirschberg, \& Shriberg, 2006). Speakers tend to use long pauses and extra fillers preceding an answer which they lack confidence in or before providing an answer which is probably wrong. Speakers also tend to use long pauses with additional fillers when they truly know the answer but incapable of retrieving it (Brennan \& Williams, 1995).

The main function of pauses in addition to expressing hesitations is that pauses have a demarcating function. In other words, silent pauses mark the word boundaries. Pauses habitually serve mark the borders between phrases, sentences and clauses, and sentence (Rose, 1998). There is a tendency for long pauses to be followed by filled pauses. Filled pauses not only mark word boundaries but also "mark stages in the discourse" (Labove \& Fanshel, 1977, p. 156). They help in organizing the whole utterance. As a motor activity, the process of speech production cannot be continuous; consequently, pauses as well as interruptions are essential in speech (Zellner, 1994).

Pauses occur as a result of the physiological necessity to continue breathing. Zellner (1994, p. 21) states that "Physiologically predictable pauses coincide with the inspiration segment of respiration since phonation is related to respiratory activity." In other words pauses perform the function of giving the chance for the speaker to take a breath which is a physiological function (Cenoz, 1998).

When it comes to the affective and cognitive functions of pauses through which the speaker uses fillers for the sake of the smoothness of the conversation, the purpose is to reflect anxiety, mental states, humility as well as hesitation, in addition to reflecting different thinking states such as looking for stored information or trying to find suitable words (Goto, Itou, \& Hayamiza, 1999). They are used as devices to plan what the speaker wants to say and when he/she tries to find the suitable words (Maclay \& Osgood, 1959; Clark \& Fox Tree, 2002). Pauses are the outer demonstration of number cognitive processes in the speech production because they supply the speaker with additional time for planning and encoding the utterance. Hence, when the speaker produces a relatively complex utterance, a speaker takes time to think before responding. In case the speaker is providing a response instantly, he/she perhaps discontinues to take time to think before starting to talk again (Zellner, 1994).

The pragmatic function is another function for pauses and hesitation markers as they express that the speaker is not sure about what he/she wants to say, politeness as well as discourse structuring (Arnold, Fagnano, \& Tanenhaus, 2003). Speakers may use pauses and hesitations in order to declare less commitment concerning the produced utterance (Brennan \& Schober, 2001). Pauses and hesitations are used when the speaker is not expected to know the answer to general knowledge questions, and when he expresses uncertainty (Brennan \& Williams, 1995). Many studies have shown that silent pauses are devices which have certain functions "either hesitation or segmentation rather than temporal variables" (Duez, 1985, p. 378). In reference to the meaning of the fillers such as um, you know and like, the widespread opinion that they have no significant meaning; they are merely hallmarks of youth (Fox Tree, 2007).

Nevertheless, recent studies have shown that these fillers have many functions as shown above. They are either gap-fillers or they can serve a discourse function that they help in processing ideas and thinking in order to produce speech (Stenstrom, 2011). Filled pauses can be used in order to gain time and accordingly to arrange the individual's ideas (Nicholson, Eberhard, \& Schuetz, 2010). Fillers also have an interactional function (Stenstrom, 2011). Besides, filled pauses play a role in the turn-taking system that they serve as a turn-holder as well as yielding the turn. They may invite the participant to take turn after a previous one has finished (Maclay \& Osgood, 1959).

\section{Methods}

Regarding data selsction two extracts from the selected plays, namely; Pinter's The Homecoming and Baker's Circle Mirror Transformation represent the corpus of this study. The researchers have chosen these two extracts because they serve the purpose of this study. The two playwrights are well known for using pauses so they are a suitable choice from the researchers' point of view. 


\subsection{Model Adapted}

The researchers will follow the sequential production approach of Sacks et al. (1974) in combination with other contributions that show the multifunctional use of pauses and hesitations to come up with an eclectic model in order to clarify the functions of pauses and hesitations. Pragmatically speaking, the pauses and hesitations are used as a device to keep the turn and to help the speakers formulate and choose suitable words when they face a problem in conveying their ideas (Maclay \& Osgood, 1959). For example, they are used as a device to keep the turn or they are used when speakers face a problem. They help the speaker formulate what to say and they give time to choose suitable words (Maclay \& Osgood, 1959).

The sequential production approach implies, according to Sacks et al. (1974), that each speaker takes part in conversation at a specific time. It is clear that in any conversation turns occur serially. What is special about the sequential production approach is that it takes into consideration verbal and non-verbal aspects, i.e., sounds and body movement as well (Wilson, Weimann, \& Zimmerman, 1984). Hence, the researchers will follow this approach in combination with the functions stated by different scholars to come up with an eclectic model that serves the purpose of this study.

\subsection{Procedure}

The procedure to be followed by the researchers is intended to enhance the reader's understanding concerning the selected texts. This procedure includes particular steps, namely specifying pauses and hesitation utterances within the selected extracts and investigating the functions of pauses and hesitations.

\section{Analysis and Discussion}

The researchers will analyze one extract from each play for the sake of investigating the different roles that pauses and hesitations may play in each text.

\subsection{The First Selected Extract (Pinter's The Homecoming)}

(Act one p.12-13) [The texts appear in the paper the same way they appear in the original texts.]

(1) SAM: Want to try one?

MAX and SAM light cigars.

You know what he said to me? He told me I was the best chauffeur he'd ever

had. The best one.

(2) MAX: From what point of view?

(3) SAM: Eh?

(4) MAX: From what point of view?

(5) LENNY: From the point of view of his driving, Dad, and his general sense of courtesy, I should say.

(6) MAX: Thought you were a good driver, did he, Sam? Well, he gave you a first- class cigar.

(7) SAM: Yes, he thought I was the best he'd ever had. They all say that, you know. They won't have anyone else, they only ask for me. They say I'm the best chauffeur in the firm.

(8) LENNY: I bet the other drivers tend to get jealous, don't they, Uncle?

(9) SAM: They do get jealous. They get very jealous.

(10) MAX: Why?

Pause.

(11) SAM: I just told you.

(12) MAX: No, I just can't get it clear, Sam. Why do the other drivers get jealous?

(13) SAM: Because (a) I'm the best driver, and because ... (b) I don't take liberties.

\subsubsection{Contextualizing the First Selected Extract}

Sam, who is a chauffeur, is having a conversation with his eldest brother Max, who is the patriarch of the family. After they light cigars, Sam tells his brother that a Yankee told him that he was the best driver among those who worked with him. Lenny (who was Max's son) is a young man engages into the conversation by telling his uncle that the other drivers might feel jealous. Max keeps asking about the reason which has made the drivers jealous by saying that "why do the other drivers get jealous?" 


\subsubsection{Analyzing the First Selected Extract}

The first selected extract contains thirteen utterances among which pauses and hesitations are distributed. This extract is taken from act one. Three characters are involved in it, namely Sam, Max and Lenny. This extract contains three different ways of expressing pauses and hesitations. The conversation which takes place between Sam and Max begins by a first pair part uttered by Sam and a second pair part uttered by Max without mentioning any kind of pauses and hesitation markers.

Utterance (2) which is a question uttered by Max is followed by utterance (3) by Sam where he has used Eh? as a question which indicates that it is used as a request for clarification. Then utterance (4) is a repetition of utterance (2) which is answered by Lenny in utterance (5) though the question is directed to Sam which emphasizes the fact that he does not know what to say. Utterance (6) is another question which is directed to Sam. After the tag question within the same utterance Max uses, well which is a verbal filler used here as a device to keep the turn after the end of the question. Utterance (12) is another first pair part directed to Sam who seems to be hesitant and not sure about what to say because he uses (...) in utterance (13) in an attempt to find suitable words (Stenstrom, 2011).

\subsection{The Second Selected Extract (Baker's Circle Mirror Transformation)}

(Act one-Week Two, pp. 12-13)

(1) MARTY:... Faster

(They all walk little faster, still going in different directions.)

(2) MARTY: ... Even faster.

(They start zooming around the room, except for Lauren, who tries to keep a safe distance away from everyone.)

(3) MARTY: Now ... I want you to slow down.

(pause.)

Start noticing everyone around you.

(They all keep walking while making an effort to notice everyone around them. Around 20 seconds pass.)

(4) MARTY: ...And I want you to find people and shake their hand.)

(They obey. 20 seconds pass.)

(5) MARTY: Now say your name when shake hands!

(About 30 seconds of walking /shaking hands / saying your own name.)

(6) MARTY: Okay! Good.

Great.

Stop.

(They stop and look at her. She smiles at them.)

(7) MARTY: How'd that feel?

(An awkward silence.)

(8) THRESA:

Great.

(9) SCHULTZ: Weird.

...Good.

(10) MARTY: Okay.

(She gets up off her ball.)

Um.

Well.

Welcome.

(Pause.)

I just ... I'm so excited to get to know all of you. 


\section{(An even longer pause.)}

I um ... I don't want to talk too much, because that's ...

(She makes a vague gesture with her hands.)

But. Um. I just hope that you all feel, um, safe here. And open.

And willing to go with it.

Ah...okay.

Let's keep going!

\subsubsection{Contextualizing the Second Selected Extracts}

This extract represents the way the class goes on. Marty gives the members of the class (who are a group of people who do not know each other) certain directions to train them. Then she tries to make them feel comfortable in that place.

\subsubsection{Analyzing the Second Selected Extract}

The scene begins with utterance (1) by Marty in which she tries to give directions to the members of the class. She begins the utterance with a silent pause (...) which indicates that she wants to put emphasis on the order. All of them respond to her order by walking faster. Again in the second utterance which is also an order, Marty uses a silent pause in initial position to emphasize the order. In the third utterance, Marty uses silent pause in the middle of the utterance after the word "know" to help her process her ideas. Marty in the fourth utterance also uses silent pause at the beginning trying to formulate what she wants to say (Stenstrom, 2011).

Utterances (1) to (6) are all only one pair uttered by the same person since they are orders. Utterance (7) which is a question directed by Marty to the members of the class followed by an awkward silence before Theresa's answer. Schultz has answered with "weird" then a silent pause (...) before saying "Good" which indicates that she is searching for suitable word to answer the question. In utterance (10), Marty has used um in initial position which indicates that there is an upcoming delay (Fox Tree, 2010) which is then followed by well as a verbal filler indicating hesitation. After welcoming them, she starts talking again then to have a silent pause before telling them that she is excited to know them. This indicates that she tries to choose suitable words. She uses um and silent pauses twice to reflect processing after the pause which is placed in a final position, she failed in choosing the suitable words so she replace words with a gesture by her hand. Then she uses $u m$ twice to reflect processing. Finally, she uses $a h$ followed by a silent pause to organize her ideas. In her last speech, she uses pauses and hesitations frequently for the sake of processing her ideas and to choose words because she talks to strangers. In one way or another, she tries to organize the discourse. She trains the group's members that she has to make ideas clear to them and to make sure that they understand what she wants them to do. Using pauses in conversation facilitate the understanding of it.

\subsection{Comparing the Two Selected Extracts}

Each one of the two writers uses pauses in different ways, each one of the pauses used has a certain function according to the context in which it occurs. In the extract selected from Pinter, there are three different forms of pauses which are: eh, well and a silent pause (...). These three different forms have different functions. Eh is used by Pinter as a request for clarification. Well is used as a device to keep the turn. The silent pause (...) is used as a device to gain time in order to find suitable words; this is on one hand. On the other hand, Baker manipulates pauses fifteen times throughout the selected extract. She uses silent pauses, um, well and ah. She uses silent pauses and $u m$ more frequently than the others. Pauses used in this extract serve various functions ranging from putting emphasis, organizing what she wants to say, searching for suitable words, referring to upcoming delay, to hesitation and processing what the character wants to say.

\section{Conclusion}

In this study the researchers follow the sequential production approach of turn taking together with the diverse functions of pauses and hesitations which are presented by different scholars. After conducting the analysis, the researchers have arrived at a number of results including that pauses and hesitations are not meaningless and not placed in the two texts randomly but they do have functions. They are valuable and play an important role in communication. Besides, the interpretation of pauses and hesitations depends on the context in which they occur. They organize the discourse and enhance understanding as well. In the extract which is taken from Pinter's The Homecoming, it is noticed that the writer has used eh, well and a silent pause (. ..). In this extract $e$ is used as a request for clarification. Moreover, well is used as a device to keep the turn. The silent pause is also used to give 
a chance for the speaker to process their thoughts. On the other hand, in the extract taken from Baker's Circle Mirror Transformation, it is noticed that the writer has used silent pauses, um and well to serve several functions ranging from adding emphasis to processing. Pauses and hesitations help the speakers in the speech production and aid listeners to understand via gaining time needed for understanding. Pauses and hesitations do not exist haphazardly in the process of speech production. On the contrary, they play important roles and serve several functions the thing which makes them an important and valuable phenomenon in speech. As far as the two selected extracts are concerned, it is obvious that Baker uses pauses and hesitations more frequently than Pinter due to the nature of the context in which they occur. Since Marty trains a group of strangers by giving directions to them, she needs to emphasize her directions and to process and organize her ideas.

\section{Acknowledgements}

The researchers of the present study are indebted to the College of Education for Women, University of Baghdad, Al-Jadiriyya, for carrying out this study.

\section{References}

Arnold, E., Fagnano, M., \& Tanenhaus, M. (2003). Disfluencies signal theee, um, new information. Journal of Psycholinguistics Research, 32(1), 25-36. https://doi.org/10.1023/A:1021980931292

Benus, S., Enos, F., Hirschberg, J., \& Shriberg, E. (2006). Pauses and deceptive speech. Prosody Speech, 18, $2-5$.

Brennan, S. E., \& Schober, M. E. (2001). How listeners compensate for disfluencies in spontaneous speech. Journal of Memory and Language, 44(2), 274-296. https://doi.org/10.1006/jmla.2000.2753

Brennan, S. E., \& Williams, W. (1995). The feeling of another's knowing: Prosody and filled pauses as cues to listeners about the metacognitive states of speakers. Journal of Memory and Language, 34, 383-398. https://doi.org/10.1006/jmla.1995.1017

Bruneau, T. J. (1973). Communicative silence: Forms and functions. The Journal of Communication, 23, 17-49. https://doi.org/10.1111/j.1460-2466.1973.tb00929.x

Cecot, M. (2001). Pauses in simultaneous interpretation: A contrastive analysis of professional interpreters' performances. The Interpreters' Newsletter, 63-85.

Cenoz, J. (1998). Pauses and communication strategies in second language speech. ERIC document reproduction service no. ED426 630.

Clark, H., \& Fox Tree, J. (2002). Using uh and um in spontaneous speaking. Cognition, 84, 73-111. https://doi.org/10.1016/S0010-0277(02)00017-3

Crystal, D. (2008). A dictionary of linguistics and phonetics (6th ed.). USA: Blakewell publishing. https://doi.org/10.1002/9781444302776

Duez, D. (1985). Perception of silent pause in continuous speech. Language and Speech, 28(4), 377-389. https://doi.org/10.1177/002383098502800403

Ekland, R., \& Wiren, M. (2010). Effect of open and directed prompts on filled pauses and utterance production. Proceedings of FONETIK. Dept. of phonetics. Centre for language and literature. Lund. Retrieved from http://www.diva-portal.org/smash/get/diva2:539502/FULLTEXT01.pdf

Fox Tree, J. (2007). Folk notion of um and uh, you know and like. Text and Talk, 27(3), 297-314. https://doi.org/10.1515/TEXT.2007.012

Fox Tree, J. (2010). Discourse markers across speakers and settings. Language and Linguistics Compass, 4(5), 269-281. https://doi.org/10.1111/j.1749-818X.2010.00195.x

Fox Tree, J. E., \& Schrock, J. C. (1999). Discourse markers in spontaneous speech: Oh what a difference an oh makes. Journal of Memory and Language, 40(2), 280-295. https://doi.org/10.1006/jmla.1998.2613

Goto, M., Itou, K., \& Hayamiza, S. (1999). A real- time filled pause detection system for spontaneous speech recognition. Proceeding of the European conference. Speech communication and technology (pp. 227-230).

Labov, W., \& Fanshel, D. (1977). Therapeutic discourse. New York: Academic Press.

Maclay, H., \& Osgood, C. (1959). Hesitation phenomena in English spontaneous speech. Word, 15(1), 19-44. https://doi.org/10.1080/00437956.1959.11659682 
Nicolson, H., Eberhard, K., \& Schuetz, M. (2010). Um ...I don't see any: The function of filled pauses and repairs. Proceedings of DiSS-LPSS Joint Workshop. Tokyo, Japan. Retrieved from https://hrilab.tufts.edu/publications/nicholsonetal10diss.pdf

O'Connell, D. C., \& Kowal, S. (2004). The history of research on the filled pause as evidence of the written language bias in linguistics. Journal of Psycholinguistic Research, 33(6), 459-474. https://doi.org/10.1007/s10936-004-2666-6

Oliveira, M. (2002). The role of pause occurrence and pause duration in the signaling of narrative structure. In E. Ranchhod \& N. J. Mamede (Eds.), Advances in natural language processing. Lecture notes in computer science. Berlin, Heidelberg: Springer. https://doi.org/10.1007/3-540-45433-0_7

Reiger, C. (2001). The perception of hesitation pauses in American Sign Language conversation. International Journal of Linguistics and Communication, 14, 33-44.

Richards, J., \& Schmidt, R. (2010). Dictionary of Language Teaching and Applied Linguistics (4th ed.). Britain: Pearson education limited.

Rose, R. (1998). The communicative value of filled pauses in spontaneous speech. (Master's thesis). University of Brimingham, United Kingdom.

Sacks, H., Schegloff, E., A., \& Jefferson, G. (1974). A simplest systematics for the organization of turn-taking for conversation. Language, 50(4), 696-735. https://doi.org/10.1353/lan.1974.0010

Stenstrom, A. (2011). Pauses and hesitations. In K. Aijmer \& Anderson (Eds.), The handbook of pragmatics: Pragmatics of society (pp. 538-567). Berlin: Walter de Gruyter.

Stepanova, S. (2007). Some features of filled hesitation pauses in spontaneous Russian. Proceedings of ICPhS (pp. 1325-1328). Saarbrucken.

Tellier, M., Stam, G., \& Bigi, B. (2013). Gesturing while pausing in conversation: Self-oriented or partner-oriented? The combined Meeting of the 10th International Gesture Workshop and Speech in Interaction Conference. Tillburg.

Tissi, B. (2000). Silent pauses and disfluencies in simultaneous interpretation: A descriptive analysis. The Interpreters' Newsletter, 10, 103-127.

Tsiaras, V., Panagiotakis, C., \& Stylianou, Y. (2009). Video and audio based detection of filled hesitation pauses in classroom lectures. 17th European Signal Processing Conference of Glasgow, Scotland.

Wang, B., \& Li, T. (2015). An empirical study of pauses in Chinese-English simultaneous interpreting. Perspectives, 23(1), 124-142. https://doi.org/10.1080/0907676X.2014.948885

Watanabe, M., \& Rose, R. (2012). Pausology and hesitation phenomena in second language acquisition. In P. Robinson (Ed.), The Routledge encyclopedia of second language acquisition (pp. 480-483). London: Routledge.

Weiling, M., Grieve. J., Bouma, G., Fruehwald, J., Goleman, J., \& Liberman, M. (2016). Variation and change in the use of hesitation markers. Language Dynamics and Change, 6(2), 199-234. https://doi.org/10.1163/22105832-00602001

Wilson, T., Weimmen, J., \& Zimmerman, D. (1984). Models of turn taking in conversational interaction. Journal of Language and Social Psychology, 3(3), 167-168. https://doi.org/10.1177/0261927X8400300301

Yuan, J., Xu, X., Lai, W., \& Liberman, M. (2000). Pauses and pause fillers in Mandarin monologue speech: The effects of sex and proficiency. 8th Speech Prosody Conference, Boston.

Zellner, B. (1994). Pauses and the temporal structure of speech. In E. Keller (Ed.), Fundamentals of speech synthesis and speech recognition (pp. 41-62). Chichester: John Wiley.

\section{Copyrights}

Copyright for this article is retained by the author(s), with first publication rights granted to the journal.

This is an open-access article distributed under the terms and conditions of the Creative Commons Attribution license (http://creativecommons.org/licenses/by/4.0/). 